\title{
Detailed Analysis of Estrous-Related Changes in Wheel Running and Self-Stimulation
}

\author{
MEIR STEINER, ${ }^{1}$ RICHARD J. KATZ AND BERNARD J. CARROLL \\ Mental Health Research Institute, Department of Psychiatry \\ University of Michigan Medical Center, Ann Arbor, MI 48109
}

Received 29 July 1980

\begin{abstract}
STEINER, M., R. J. KATZ AND B. J. CARROLL. Detailed analysis of estrous-related changes in wheel running and self-stimulation. PHYSIOL. BEHAV. 28(1) 201-204, 1982.-Previous studies have demonstrated that a number of behaviors change their probability of occurrence during the estrous cycle. Wheel running is known to show estrous-related changes while reports upon intracranial reinforcement (self-stimulation, ICS) have been equivocal. The present studies examined both behvaiors to further resolve the underlying behavioral determinants of these estrous effects. Data for wheel running and intracranial self-stimulation behaviors of adult female Holtzman rats were collected nightly on a minute by minute basis across the estrous cycle. It was found that: (a) both behaviors showed significant estrous-related changes in frequency; (b) the two behaviors occurred in discontinuous episodes (bursts) during the dark phase of the diurnal cycle; and (c) of three burst parameters (number/session, average length, rate of response), number proved the best predictor of estrous-related behavioral change. Burst number may reflect an important motivational parameter underlying estrousrelated changes in behavior.
\end{abstract}

Wheel running (WR) Intracranial self-stimulation (ICS) Estrous cycle

MANY behaviors, when observed under steady state conditions (during periods of continuous free access) assume a non-random, episodic character. This tendency towards discrete organization appears to be prevalent particularly in motivated behaviors. Thus feeding and drinking [10], exploratory behavior and wheel running $[12,13]$, as well as selfstimulation $[1,7]$, have all been shown to occur in bursts.

Episodes may be characterised by measuring a number of parameters, including: (a) total number of bursts of activity per session (i.e., number); (b) the average length of each episode and (c) the response density, i.e., the number of responses per unit time within the burst.

Intracranial self-stimulation is resistant to satiation, and the capacity of stimuli to activate the positive reinforcement system seems to change as a function of change in the drive state [18]. Some data indicate that the performance of intact regularly cycling female rats in pressing a bar for electrical stimulation of the hypothalamus changes during the estrous cycle $[11,14,16]$. Others were unable to confirm such a positive relationship $[2,4,9,15]$. In one experiment the hormonal induction of estrous behavior in ovariectomized rats had no effect on septal self-stimulation [5]. We have recently shown that specific increases in wheel running and intracranial self-stimulation are estrous-related [17]. Other changes in behavior across the estrous cycle have also been well established [19]. The following experiment was aimed at de- termining whether the above behaviors also had similar episodic patterns of occurrence across the estrous cycle. Number, length, and density rate of response of wheel running and self-stimulation episodes were examined for behavioral similarities and for their relationships with other patterns of behavioral change. The particular hypotheses tested were that both behaviors had similar intrinsic patterns, which would be reflected in a covariation of one or more burst parameters with total response level.

\section{METHOD}

For wheel running twenty experimentally naive, adult, female rats (Holtzman, WI), 245-275 grams body weight, were housed individually in $36 \mathrm{~cm}$ diameter activity wheels (Lafayette Instruments Comp., IN), under controlled conditions of temperature $\left(21^{\circ} \mathrm{C}\right)$ and illumination (lights on from 0545 to 1815 hours). Teklad $4 \%$ fat rodent diet and tap water were available ad lib. Estrous cycles were followed by daily vaginal smears.

\section{Procedure}

A Veeder recording counter was connected to each drum to count the revolutions of the wheels in either direction. Microswitches, attached to the hub registered the revolutions and data were stored on a teletype punch. Starting with

${ }^{1}$ Please address all correspondence to Dr. Steiner, now at McMaster Psychiatric Unit, St. Joseph's Hospital, 50 Charlton Avenue East, Hamilton, Ontario, L8N 1 Y4 Canada. 
The Bursting Phenomenon in Wheel Running

Across the Estrus Cycle $(n=20)$
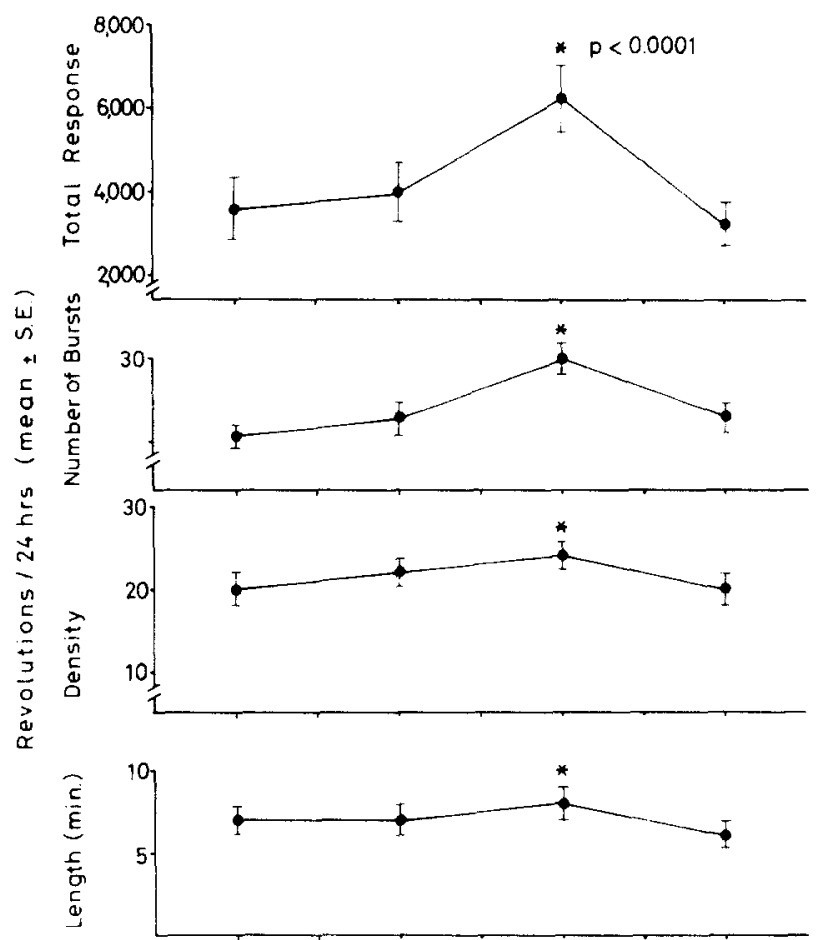

Diestrus-1| Diestrus-2 | Proestrus | Estrus |Diestrus-1

FIG. 1. Total and discrete behavioral changes in wheel running activity of female rats across the estrous cycle $(n=20)$. Note that three weeks of initial experimental habituation preceded the measurements presented in this figure.

the third week in the wheels (following an adjustment period) the data from one complete 4-day estrous cycle for each animal were analyzed. Through this cycle activity was recorded during the dark period (1815 to 0545 hours) on a minute by minute basis (revolutions per minute).

Three parameters were analyzed: (1) the number of distinct bursts per night; (2) the average length of each burst in minutes; and (3) the density (i.e., running rate). The criteria for these were as follows: (1) the number of bursts was defined by the number of zero/non-zero transitions during one night; (2) the average length was defined as the total number of non-zero intervals (minutes) divided by the number of bursts per night; and (3) density (running rate) was calculated by the total number of responses per night divided by the total number of non-zero intervals (minutes). Individual nightly scores were combined for a group of analysis of the data using repeated measures analyses of variance and multiple regression analysis [3]. Data are presented throughout as means and standard errors.

For self-stimulation twelve experimentally naive, adult, female rats (Holtzman, WI), 240-280 grams body weight

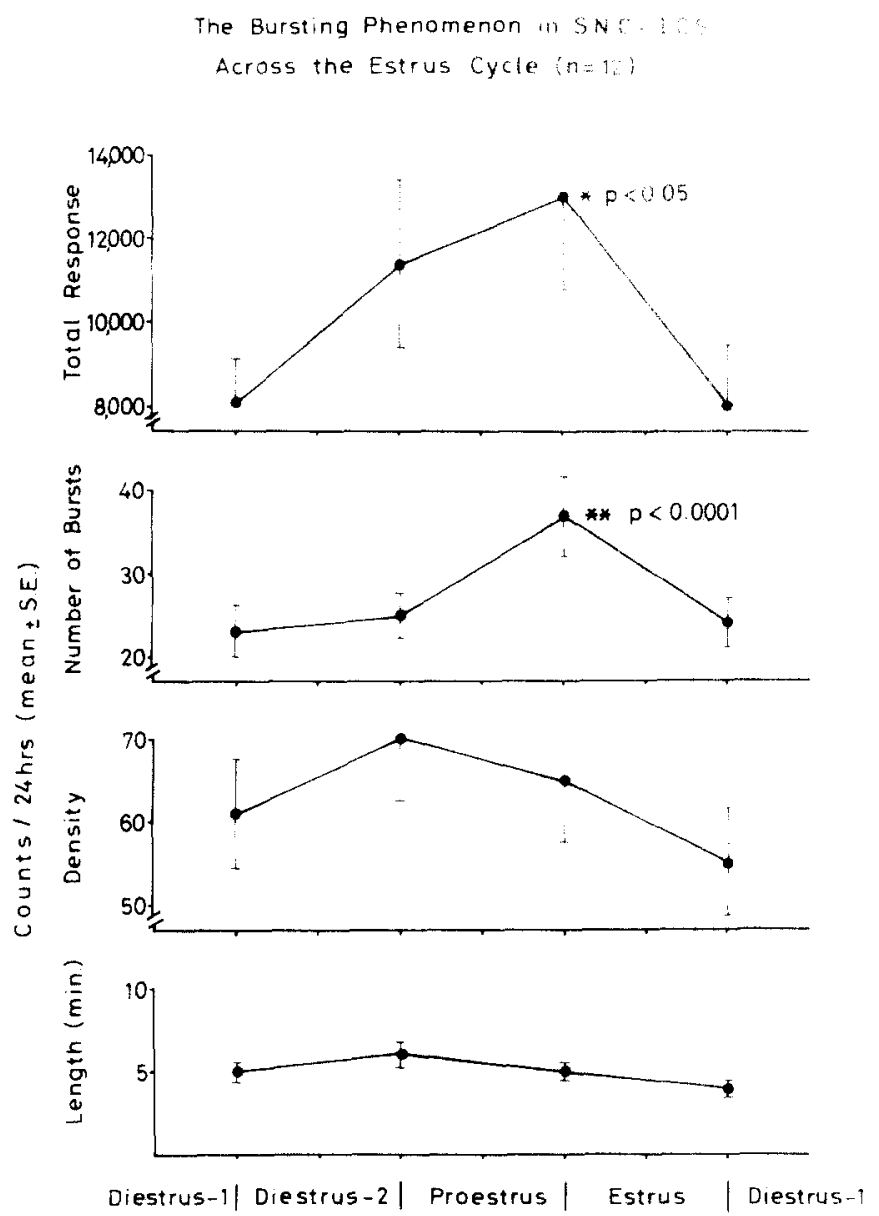

FIG. 2. Total and discrete behavioral changes in intracranial selfstimulation across the estrous cycle $(n=12)$. Note that three weeks of recovery from surgery preceded the measurements presented in this figure.

were housed under the same controlled conditions as described in the Wheel Running experiment. We have routinely used sample sizes of this magnitude in selfstimulation studies and found them to be adequate for the assessment of behavior (e.g., [7]).

\section{Surgery}

Animals were anesthetized with sodium pentobarbital (Nembutal, IP $50 \mathrm{mg} / \mathrm{kg}$ body weight) and stereotactically implanted with unipolar $0.25 \mathrm{~mm}$ diameter nichrome wire electrodes insulated to the tip. Electrodes were aimed at the pars compacta of the substantia nigra (SNC) using the coordinate system of König and Klippel [8] $(5.0 \mathrm{~mm}$ posterior to the bregma, $1.5 \mathrm{~mm}$ lateral to the midline, and $8.0 \mathrm{~mm}$ deep; top of the skull coordinates, zero line at bregma $=A$ 7200). The electrodes were attached to a head-mounted brass brushing which was secured to the skull with stainless steel screws and acrylic dental cement.

\section{Apparatus}

Standard $25 \times 18 \times 17 \mathrm{~cm}$ stainless steel cages were mod- 
TABLE 1

NIGHTLY BURSTING PATTERN IN WHEEL RUNNING ACROSS THE ESTROUS CYCLE $(\mathbf{N}=20)$

\begin{tabular}{|c|c|c|c|c|c|}
\hline & $D_{1}-D_{2}$ & $\mathrm{D}_{2}-\mathrm{P}$ & P-E & E-D & $\begin{array}{c}\text { ANOVA } \\
p\end{array}$ \\
\hline Response & $3612 \pm 679.00$ & $4014 \pm 701.00$ & $6237^{*} \pm 879.00$ & $3231 \pm 557.00$ & $<0.0001$ \\
\hline Bursts & $21 \pm 1.00$ & $23 \pm 1.70$ & $30^{*} \pm 1.70$ & $23 \pm 1.40$ & $<0.0001$ \\
\hline Length & 0.80 & 0.80 & $8^{*} \pm$ & $6 \pm$ & $<0.0001$ \\
\hline Density & $20 \pm$ & $20 \pm$ & $24^{*} \pm$ & $20 \pm$ & $<0.0001$ \\
\hline
\end{tabular}

Legend: $D_{1}=$ Diestrus-1; $D_{2}=$ Diestrus-2; $P=$ Proestrus; $E=$ Estrus. $D_{1}-D_{2}, D_{2}-P$, etc., represents the night between the two corresponding days. Response $=$ the total counts per night. Bursts $=$ the number of distinct bursts per night. Length $=$ the average length of each burst in minutes. Density $=$ the mean number of counts per minute within the bursts. ${ }^{*}=$ the peak for the statistical significance.

TABLE 2

THE NIGHTLY BURSTING PATTERN IN INTRACRANIAL SELF-STIMULATION ACROSS THE ESTROUS CYCLE $(\mathrm{N}=12)$

\begin{tabular}{|c|c|c|c|c|c|c|c|c|}
\hline & $D_{1}-D_{2}$ & \multicolumn{2}{|c|}{$\mathrm{D}_{2}-\mathrm{P}$} & \multicolumn{2}{|c|}{ P-E } & \multicolumn{2}{|c|}{$\mathrm{E}-\mathrm{D}_{1}$} & $\begin{array}{c}\text { ANOVA } \\
p\end{array}$ \\
\hline Response & $8145 \pm 1521.0$ & $11405 \pm$ & 07.0 & $12937^{*} \pm$ & 07.0 & $8050 \pm$ & 63.0 & $<0.05$ \\
\hline Bursts & $23 \pm \quad 3.0$ & $25 \pm$ & 2.7 & $37^{*} \pm$ & 4.8 & $24 \pm$ & 3.1 & $<0.0001$ \\
\hline Length & $5 \pm$ & $6 \pm$ & 0.8 & $5 \pm$ & 0.5 & $4 \pm$ & 0.3 & N.S. \\
\hline Density & $61 \pm$ & $70 \pm$ & 7.3 & $65 \pm$ & 7.3 & $55 \pm$ & 6.6 & N.S. \\
\hline
\end{tabular}

Legend: Same as for Table 1.

ified to allow chronic self-stimulation using the method of Wolf, DiCara, and Simpson [20]. The wire mesh floor served as a stimulation ground and a hinged mounted overhead $14 \times 16 \mathrm{~cm}$ stainless steel plate served as a manipulandum and contact for current delivery. Upwards displacement of the overhead panel allowed circuit completion and stimulation delivery through the brushing mounted on the animal's head. Self-stimulation was continuously available 24 hours/day without external leads and consisted of 300 millisecond trains of monopolar 60 cycles-per-second sinusoidal current, $45-110 \mu \mathrm{A}$ in intensity.

\section{Procedure}

The implanted animals were placed in the modified cages and the current was turned on. After $3-4$ days of initial "shaping" sessions, the animals were allowed 2 additional weeks of ad lib self-stimulation in which rates stabilized. Starting with the third post-operative week, intracranial selfstimulation data were recorded for one complete 4-day cycle for each animal. Activity during the dark period was recorded on a minute by minute basis (intracranial selfstimulation counts per minute). Monitoring and data analysis of bursts were done as in the Wheel Running experiment.

\section{RESULTS}

For wheel running all animals maintained highly regular 4-day estrous cycles throughout the experiment. The nightly bursting pattern of wheel running for 20 animals across the cycle is summarized in Table 1 and in Fig. 1. As shown, all animals maintained a highly significant peak on "the night of behaviôral estrus"' (see Total Response on the night between the days of proestrus and estrus (P-E). In addition, all 3 measures of the bursting phenomenon, i.e., the number of bursts, the average burst length and the density, were significantly higher on that night. However, it is apparent from Fig. 1 that the increase in the total number of revolutions during the night of behavioral estrus is mostly due to the increase in the number of bursts. This was confirmed statistically using multivariate analysis.

Multiple regression analysis for the contributions of the three parameters to the total variance of wheel running indicated B coefficients of $0.27,0.31$, and 0.67 for length, density, and number of bursts respectively; thus standardized B-weights confirmed the trend which was present by visual inspection.

For self-stimulation, all animals maintained highly regular 4-day estrous cycles throughout the experiment. The nightly bursting pattern of intracranial self-stimulation with electrodes in the pars compacta of the substantia nigra for 12 animals across the cycle is illustrated in Table 2 and in Figure 2. The behavioral cyclicity in intracranial self-stimulation with its significant peak on P-E was prominent. The only bursting parameter which also maintained a highly significant peak on P-E was the number of bursts. The two other dimensions were not significantly different across the 4 nights of the cycle. Thus the peak in intracranial selfstimulation on "the night of behavioral estrus" is totally ac- 
counted for by the increase in the number of bursts on that night. Histology by the method of Hosko [6] confirmed that all electrode placements were within the intended nucleus. the pars compacta of the substantia nigra. (A more detailed graphic histology has been provided [17].)

\section{DISCUSSION}

A study of the various dimensions of the bursting phenomenon across the estrous cycle of the rat has not been previously documented. Since the concepts evolving around bursting are still hypothetical and speculative, the results obtained in these experiments are open for interpretations.

If the outcome of the bursting analysis in wheel running and intracranial self-stimulation is looked at in view of our results, one possible interpretation might be that both behav iors have closely related underlying mechanisms: (a) Wheel running and intracranial self-stimulation follow a chronologically similar pattern of behavioral cyclicity across the estrous cycle. (b) Both behaviors have a synchronized, statisti. cally significant increase and peak on "the night of behavioral estrus." (c) The number of bursts per night is the parameter that best correlates with this specific increase in both behaviors.

Previous studies have indicated that both behaviors may serve as primary reinforcers. It has been hypothesized that an increase in the number of bursts reflects an increase in incentive. If this is true, then the incentive-priming model of reward appears to gain empirical support from bursting analysis.

\section{REFERENCES}

1. Annau, Z., R. Heffner and G. F. Koob. Electrical selfstimulation of single and multiple loci: Long term observations. Physiol. Behav. 13: 281-290, 1974.

2. Drewett, R. F. and L. J. Herberg. Hypothalamic selfstimulation in the female rat: Effects of oestrus and food deprivation. Physiol. Behav. 14: 285-289, 1975.

3. Fox, D. J. and K. E. Guire. Documentation for MIDAS, $3 \mathrm{rd} \mathrm{ed.}$ Ann Arbor, MI: The University of Michigan Statistical Research Laboratory, 1976.

4. Hitt, J. C. and A. A. Gerall. Effect of brain stimulation on estrous activity cycles. Psychol. Rep. 24: 59-68, 1969.

5. Hodos, W. and E. S. Valenstein. Motivational variables affecting the rate of behavior maintained by intracranial stimulation. J. comp. physiol. Psychol. 53: 502-508, 1960.

6. Hosko, M. J. Technique for rapid permanent documentation of intracerebral electrode sites. Physiol. Behav. 14: 367-368, 1975.

7. Katz, R. J. The temporal structure of reinforcement: An analysis of brain stimulated reward. Behav. Neural Biol. 26: $416-430,1979$.

8. König, J. F. R. and R. A. Klippel. The Rat Brain: A Stereotaxic Atlas of the Forebrain and Lower Parts of the Brain Stem. Huntington, NY: Robert E. Krieger, 1963.

9. Lenzer, I. I. Food deprivation, estrogen levels and selfstimulation in the female rat. Psychol. Rep. 29: 655-665, 1971.

10. Levitsky, D. A. Feeding conditions and intermeal relationships. Physiol. Behav. 12: 779-787, 1974.

11. Moss, R. L. Changes in bar press duration accompanying the estrous cycle. J. comp. physiol. Psychol. 66: 460-466, 1968.
12. Premack, D. and W. A. Kintsch. A description of free responding in the rat. Learn. Motivat. 1: 321-336, 1970.

13. Premack, D., R. W. Schaeffer and A. Hundt. Reinforcement for drinking by running: Effect of fixed ratio and reinforcement time. J. exp. Analysis Behav. 7: 91-96, 1964.

14. Prescott, R. G. W. Estrous cycle in the rat: effects on selfstimulation behavior. Science 152: 796-797, 1966.

15. Rosenquist, A. Wheel running motivated by electrical stimula tion of the lateral hypothalamus in the rat. Princeton University. Ph.D. Dissertation, University Microfilms, Ann Arbor, MI 1968.

16. Scott, T. R., Jr. and B. G. Hoebel. Effect of sex hormones on lateral hypothalamic self-stimulation and feeding. Am. Zool. 6: $537,1966$.

17. Steiner, M. Motivated behavior and the estrous cycle of the rat. University of Michigan Ph.D. Dissertation, University Microfilms, Ann Arbor, MI, 1979.

18. Valenstein, E. S. History of brain stimulation: investigations into the physiology of motivation. In: Brain Stimulation and Motivation, edited by E. S. Valenstein. Glenview, IL: Scott, Foresman and Co., 1973, pp. 1-43.

19. Wang, G. H. The relation between "spontaneous" activity and the estrous cycle in the white rat. Comp. Psychol. Monour. 2: $1-27,1923$.

20. Wolf, G., L. V. DiCara and W. Simpson. The contact method: A simple technique for electrical self-stimulation without external leads. Physiol. Behav. 11: 721-723, 1973. 